\section{The effects of open-field size on activity in the Mongolian gerbil}

\author{
JEFFREY OLDHAM and HENRY MORLOCK* \\ State University College, Plattsburgh, N.Y. 12901
}

Locomotor activity of 15 Mongolian gerbils was recorded in five open fields of different sizes. Consistent with previous findings for rats and other rodents, activity increased with field size and decreased with time in the field. Amount of defecation was not related to field size or activity.

Montgomery (1951) found that locomotor activity in rats increased as the size of the observation area increased. Broadhurst (1957) also reported that rats were more active in the larger of two open fields. The purpose of the present study was to test the generality of this relationship using Mongolian gerbils as Ss. Previous research on gerbils has indicated that they differ from rats in showing more locomotion and more frequent, longer occupancy of the central area of an open field (Nauman, 1968). Further, latency to enter an open field is less for a larger than for a smaller field (Walter, Pearl, \& Rogers; 1963). Apparently, however, there has been no study that directly investigated the relationship between amount of locomotor activity and size of the field in gerbils.

\section{SUBJECTS}

Fifteen male Mongolian gerbils were used. All were about 3 months old and were acquired from Tumble Brook Farms, Brant Lake, New York. The Ss were housed in individual cages $\left(91 / 2 \times 7 \times 7 \frac{1}{2}\right.$ in.) and maintained ad lib on Big Red Laboratory Chow and water. The cages contained wooden floors and wood shavings.

\section{APPARATUS}

The apparatus consisted of five open fields: $18 \times 9$ in., $18 \times 18$ in., $36 \times 18$ in., $36 \times 36$ in., and $72 \times 36$ in. The walls were 12 in. high. White glossy paint was used for the interior of the fields, and thin blue lines, forming 3-in. squares, were painted on the inside floors. The Ss were admitted to the fields from a glossy white startbox, $4 \times 7 \times 31 / 2$ in. The opening of the startbox measured $3 \times 3 \frac{1}{2}$ in., and a white guillotine

*Requests for reprints should be addressed to Henry Morlock, Division of Social Science. State University College, Plattsburgh, N.Y. 12901. door was used for a gate. Wire screen covered the top of the startbox. Observations of each trial were made from behind a $6 \times 4 \mathrm{ft}$ white screen. A 150 -W light, 25 in. above the center of each field was the only source of illumination. A fan provided air circulation and a masking noise.

\section{PROCEDURE}

A within-S design was used to expose each $S$ to each one of the experimental conditions. The order of exposure to the five fields for each $\mathbf{S}$ was randomized. The experiment required 15 days, and the day in which a particular $S$ was tested in a particular condition was also randomized. Before the start of each trial, $S$ was placed in the startbox for $30 \mathrm{sec}$. After this, $S$ was admitted to the open field for $10 \mathrm{~min}$. Number of squares traversed and number of fecal boluses excreted were counted per minute. After each trial the entire field was wiped down with a wet cloth in order to remove any residue left by the $S$

RESULTS AND DISCUSSION

Amount of activity (number of squares traversed per minute), see Fig. 1, increased

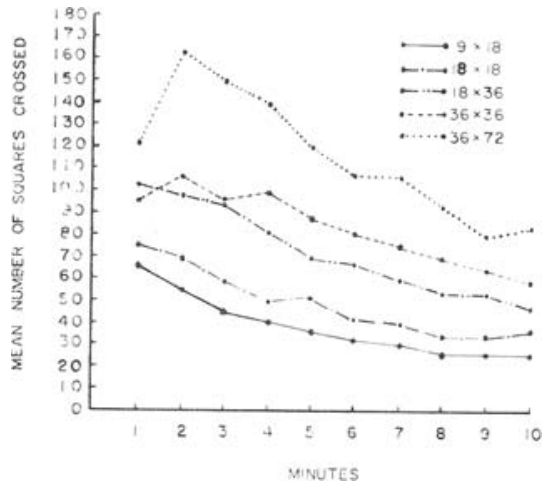

Fig. 1. Mean number of squares crossed in each of the five fields per minute. significantly as the size of the test area increased $[F(4,56)=134.47, \quad p<.05]$. This result supports the earlier findings of Walters et al and is consistent with the results of the rat studies of Broadhurst and Montgomery. Thus, the positive relationship between activity and field size reported for the rat can be generalized to the gerbil.

It was also found that the amount of activity decreased significantly with the amount of time spent in each of the five test areas $[F(9,126)=100.32, p<.05]$. This finding is consistent with that of Glickman \& Hartz (1964) who found that both the gerbil and the rat, as well as other rodents, exhibited a decline in activity with time spent in an area.

A significant interaction $[F(36,504)=4.43,. p<.05]$ between field size and time spent in the field was also present. As shown in Fig. 1, the interaction appears to be the result of a difference in rate of clecline in activity between the largest and the other fields, a higher rate of decline being displayed in the largest.

The majority of Ss defecated in all the fields, and the amount of defecation for each of the five fields was not significantly different $[F(4,70)=.69, p>.05]$. The mean number of boluses for the five fields ranged from 6.4 to 8.6 . The fact that defecation was observed is somewhat inconsistent with the observations of Glickman and Hartz, who reported that their gerbils did not defecate in the field.

Pearson correlation coefficients were calculated between the activity scores and the amount of defecation for each condition. These computations were made for the $1 \mathrm{st} \mathrm{min}$, the first $5 \mathrm{~min}$, and the entire $10-\mathrm{min}$ period of each trial. The correlations were small and none were statistically significant. Thus, unlike rats (Hall, 1936), gerbils apparently do not show an inverse relationship between activity and defecation.

\section{REFERENCES}

BROADHERST, P. L. Determination of cmotionality in the rat. I. British Joumal of Psychology, 1957, 48, 1-12.

GLICKMAN, S., \& HARTZ, K. Exploratory behavior in several species of rodents. Journal of Comparative \& Physiological Psychology, 1964, 58, 101-104.

HALL, C. Emotional behavior in the rat. III: The relationship between emotionality and ambulatory activity. Journal of Comparative \& Physiological Psychology, 1936, 22, 345-352.

MONTGOMERY, K. C. The relation between exploratory behavior and spontaneous alternation in the white rat. Journal of Comparative \& Physiological Psychology, $1951,44,582-589$.

NAUMAN, D. J. Open-field behavior of the Mragolian gerbil. Psychonomic Science, 1968 $10,163-16.4$.

WALTERS, G. C., PEARI, J., \& ROGERS, J. V. The gerbil as a subject in behavioral research. Psychological Reports, 1963, 12, 315-318. 